\title{
Relationship between mandibular symphysis dimensions and skeletal pattern in adults
}

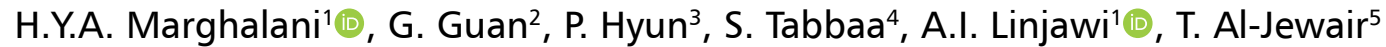 \\ 'Orthodontic Department, Faculty of Dentistry King Abdulaziz University, Jeddah, Saudi Arabia \\ ${ }^{2}$ Department of Orthodontics, University of Pennsylvania, Philadelphia, United States \\ ${ }^{3}$ Private Practice, Albany, NY, United States \\ ${ }^{4}$ School of Orthodontics, Jacksonville University, United States \\ ${ }^{5}$ Department of Orthodontics, School of Dental Medicine, University of Buffalo, NY, United States
}

[Received: 12 March 2021; Accepted: 19 April 2021; Early publication date: 29 April 2021]

Background: The knowledge of dimensions of the symphysis is important for morphological and orthodontic studies. This research evaluates the association between mandibular symphysis dimensions and anteroposterior and vertical skeletal patterns in adults.

Materials and methods: This cross-sectional cephalometric study included 90 lateral cephalograms of untreated subjects presenting for orthodontic treatment. The inclusion criteria were adults with lateral cephalograms showing the symphyseal region and anterior cranial base. One investigator traced and analysed all cephalograms. Symphyseal height, thickness, and ratio between height and thickness were measured in relation to seven anteroposterior and vertical skeletal measurements in females and males.

Results: Symphyseal measurements were associated with SNA (anteroposterior) in females and Gonial angle (vertical) in males. When analysed by anteroposterior skeletal classification $\left(A N B^{\circ}\right)$, no significant differences in symphyseal dimensions were found. Multiple linear regression analyses showed that Gonion-Nerve $(\mathrm{mm})$ and Gonial angle were significantly associated with symphyseal height. Gonion-Nerve $(\mathrm{mm})$, basal bone width $(\mathrm{mm})$, and alveolar bone height $(\mathrm{mm})$ were associated with symphyseal thickness. Basal bone width $(\mathrm{mm})$ and alveolar bone height $(\mathrm{mm})$ were associated with symphyseal ratio.

Conclusions: Symphyseal dimensions were significantly associated with vertical but not anteroposterior skeletal patterns. Future studies are warranted to evaluate the Gonion-Nerve measurements concerning the symphysis in relation to vertical and anteroposterior skeletal patterns. (Folia Morphol 2022; 81, 2: 464-471)

Key words: mandible, skeletal patterns, dimensions, symphysis

\section{INTRODUCTION}

The mandibular symphysis plays an essential role in determining the profile of patients and is important part of the mandible anatomy. The boundaries of the dentoalveolar symphysis can define the limits of orthodontic tooth movement since larger symphysis may allow for the proclination of the lower incisors [2]. Hence, the dimensions of the mandibular symphysis can serve as important diagnostic tool in the orthodontic treatment planning because of its anatomical importance. 
The growth of the symphysis shows changes from childhood to adulthood in both sexes. Males demonstrate larger and later changes in symphyseal dimensions as compared to females [2]. With age, the symphyseal angle (measured between the mandibular plane and a line between the lowest point on the symphysis, or Menton and the deepest point on the anterior concavity of the symphysis, or B-point) decreases and the reduction is more significant in males than in females [2]. Also as age increases, the ratio between symphysis height and thickness also increases [2]. Symphysis ratio is important for the assessment of chin morphology. A smaller symphysis ratio, more common in males, indicates a prominent chin while a larger ratio denotes a receding chin [2].

Studies have found that symphysis ratio and morphology are strongly associated with mandibular growth direction, especially in males [2, 12]. Dolicofacial subjects (with long face) have thinner and longer dentoalveolar and basal symphyses and greater lingual dentoalveolar inclination than brachyfacial subjects (with short face) [4]. The average thickness of the symphysis at the mandibular incisor apex region is $7.32 \mathrm{~mm}, 8.72 \mathrm{~mm}$, and $9.94 \mathrm{~mm}$ in dolicofacial, mesofacial and brachyfacial groups, respectively [4].

Moreover, vertical skeletal pattern may also influence symphysis height. A study by Ceylan et al. [7] found that mandibular dentoalveolar heights and symphyseal height and area were greater in individuals with open bites and shorter and wider in subjects with deep bites. Overall, males showed greater vertical growth rate than females in the upper $20 \%$ of the symphysis. The average height of the symphysis in adults with normal occlusion and well-balanced faces is $47 \mathrm{~mm}$ in males and $42.5 \mathrm{~mm}$ in females [4].

The symphysis may be affected by anteroposterior skeletal classification. Class I skeletal pattern has normal relationship of the maxilla (SNA) to the mandible position (SNB) measured by ANB angle. Class II skeletal pattern has backward position of mandible (large ANB value) and class III has advanced position of the mandible (less ANB value). Previous literature found that class III skeletal pattern is associated with smaller angle of the anterior concavity of the symphysis compared to class I and II. Also, the alveolus of the mandibular incisor is closer to the mandibular plane. Class III subjects also have larger symphysial area than class I or II [5].

Evaluating the symphyseal height, thickness, and ratio is essential knowledge to the anatomy and morphology of the mandible. The aim of this study was to evaluate the symphyseal morphology in adults presenting with different anteroposterior and vertical skeletal patterns. We hypothesized that there will be no significant association between symphyseal and skeletal features.

\section{MATERIALS AND METHODS}

This cross-sectional cephalometric study was conducted between 2016 and 2017 using lateral cephalograms selected from Caucasian subjects presenting for orthodontic treatment at one orthodontic clinic. Ethical approval was obtained from the University at Buffalo Institutional Review Board (\#419644-4). The inclusion criteria were adults 18 years old or above with pre-treatment lateral cephalograms that clearly displayed the symphyseal region and anterior cranial base. Exclusion criteria were history of orthodontic treatment or orthognathic surgery, missing teeth other than third molars, craniofacial anomalies or syndromes, musculoskeletal disorders, and history of trauma. Sample size estimation showed that a minimum of 85 records were needed to detect a correlation of $r=0.3$ or above between variables with a significance level of $5 \%$ and power of $80 \%$.

A total of 90 lateral cephalograms met the inclusion criteria for this study from a pool of 5299 pre-treatment records organised by year. The sample included 44 females and 46 males with age range of 18-44 years old. Lateral cephalograms then were traced and analysed by one author (H.M.) using Dolphin imaging software (Version 11.7.05.66 Premium; Dolphin Imaging and Management Solutions, Chatsworth, California). The study used modified landmarks from those presented by Chung et al. [8] and Suri et al. [17] (Fig. 1). The posterior alveolar point (PAP), the most inferior and posterior point on the anterior border of the ramus, as defined by Suri et al. [17] was hard to locate on the cephalograms. Therefore, a modification to this analysis was made. The analysis utilised the bisecting line of the Gonial angle (formed by lines tangent to the lower and posterior parts of the mandible) to locate the 'nerve' point. This point is the intersection of that line with inferior alveolar nerve. Ten linear and angular measurements were used for this study. Symphyseal measurements included the height, thickness, and ratio of height to thickness. Anteroposterior and vertical skeletal measurements included the $\mathrm{SNA}^{\circ}, \mathrm{SNB}^{\circ}, \mathrm{ANB}^{\circ}$, alveolar bone height $(\mathrm{mm})$, basal bone width $(\mathrm{mm})$, Ar-Go$-\mathrm{Me}^{\circ}$ (Gonial angle), and Gonion-Nerve distance $(\mathrm{mm})$. 


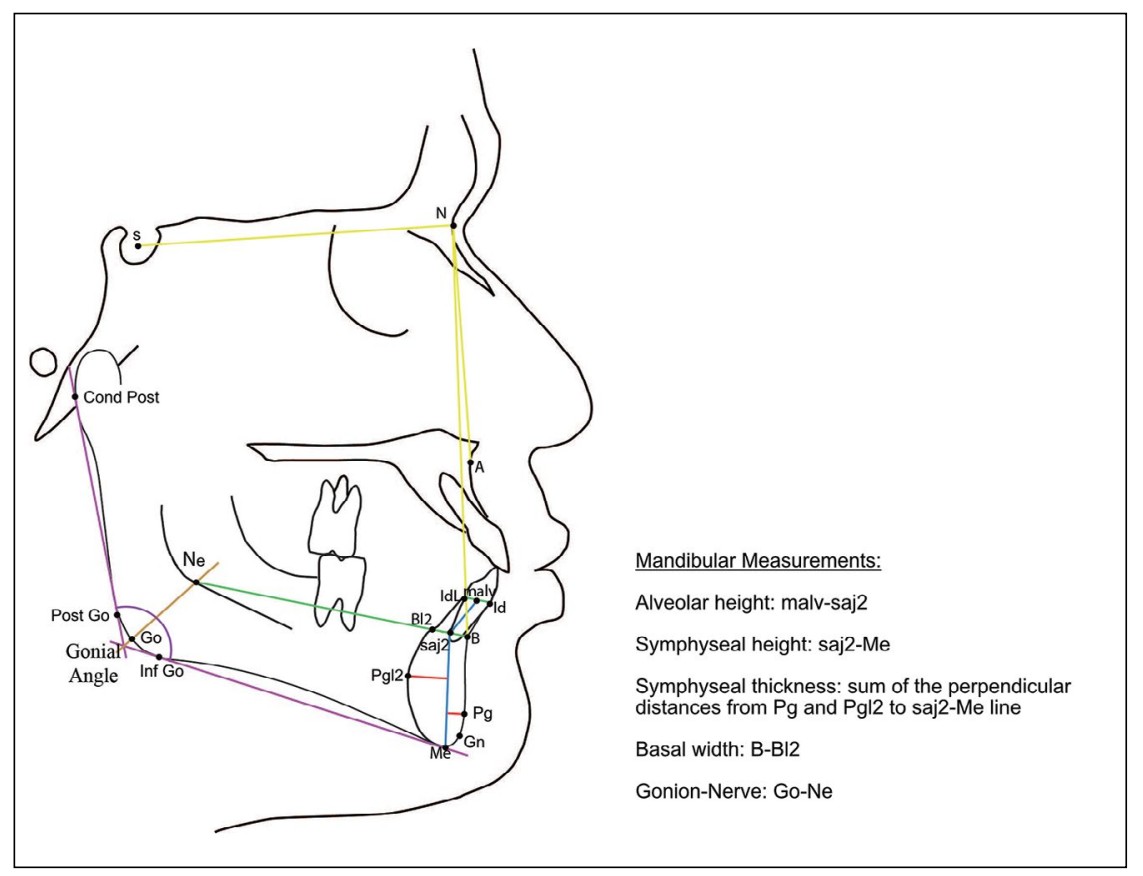

Figure 1. Landmarks and measurements used in this study. $\mathrm{N}$ - nasion; $\mathrm{S}$ - sella; Point $\mathrm{A}$ - subspinale; Point $\mathrm{B}$ - supramentale; Id — infradentale; $\mathrm{Pg}$ — pogonion; $\mathrm{Gn}$ — gnathion; $\mathrm{Me}$ — mention; $\mathrm{Go}$ - Gonion. Other Landmarks: Gonial Angle — formed by the intersection of 2 lines; one from Menton (Me) to Inferior Gonion (Inf Go) and the other from Condyle Posterior (Cond Post) to Posterior Gonion (Post Go); Nerve (Ne) - formed by a line that bisects Gonial angle (formed by the intersection of the previous two lines which intersects with inferior alveolar nerve at $\mathrm{Ne}$ ); $\mathrm{BI} 2$ - the point of intersection of a line drawn from Ne to B, with the lingual surface of symphysis; saj2 — the midpoint of a line drawn from BI2 to B; Pgl2 — the furthest point on the lingual contour of the symphysis, located by the largest perpendicular distance from a line drawn from the saj2 to Me; malv — middle point of a line drawn from Idl to Id. Mandibular measurements: alveolar height — distance of a line drawn from malv to saj2; symphyseal height — the line drawn from saj2 to Me; symphyseal thickness — the sum of the distances of the perpendiculars from $\mathrm{Pg}$ and $\mathrm{Pgl} 2$ to a line drawn from saj2 to Me; basal width — distance of a line drawn from $\mathrm{BI} 2$ to $\mathrm{B}$; Gonial angle: angle formed by the intersection of two lines (Post Go-Condyle Posterior and Me-Inf Go); Gonion-Nerve (mm): distance from the intersection of two lines (Post Go-Condyle Posterior and Me-Inf Go) and Ne point in mm.

\section{Statistical analysis}

Ten cephalograms were randomly chosen and re-measured by one author (H.M.) to assess the intra-examiner reliability using intraclass correlation coefficient (ICC). Data were analysed using SPSS software (PASW statistics version 19). Pearson correlation coefficients between each of the independent variables $\left(\mathrm{ANB}^{\circ}, \mathrm{SNA}^{\circ}, \mathrm{SNB}^{\circ}\right.$, alveolar height, basal width, Gonial angle, and Gonion-Nerve distance) with the dependent variables (symphysis height, thickness, and ratio) were assessed. Correlations between anteroposterior skeletal classification and symphyseal variables were calculated according to $\mathrm{ANB}^{\circ}$ values $\left(1-4^{\circ}=\right.$ class I; more than $4^{\circ}=$ class II; and less than $1^{\circ}=$ class III). Correlation strengths were analysed according to Evans [9]. Multiple linear regression analyses were conducted to determine strength of association between symphyseal height, thickness, and ratio with multiple independent variables. Significance was set at $5 \%$.

\section{RESULTS}

\section{Intra-examiner reliability}

There was significant correlation between the repeated measurements for all variables with the ICC ranging from 0.97 to 0.82 (Table 1 ).

\section{Descriptive statistics}

Table 1 presents the mean skeletal measurements according to sex. Overall, the mean $\mathrm{ANB}^{\circ}$ was $2.3^{\circ}$ (standard deviation [SD] of 3.1). The mean SNA ${ }^{\circ}$ and $\mathrm{SNB}^{\circ}$ were $82.5^{\circ}\left(\mathrm{SD}\right.$ of $3.8^{\circ}$ ) and $80.2^{\circ}$ (SD of $3.95^{\circ}$ ), respectively. Significant differences between males and females were noted for $\mathrm{ANB}^{\circ}(p=0.003)$ and Gonion-Nerve distance ( $p<001)$.

Table 2 presents the means for the outcomes of interest: symphysis height, thickness, and ratio according to sex. They were significantly different between females and males with a general trend of being smaller in females compared to males. For example, the symphyseal thickness in females was 
Table 1. Mean anteroposterior and vertical skeletal measurements in females $(n=44)$ and males $(n=46)$

\begin{tabular}{|c|c|c|c|c|c|}
\hline Variable & Sex & Mean & SD & Median & Significance* \\
\hline $\mathrm{ANB}^{\circ}$ & $\begin{array}{c}\text { Female } \\
\text { Male }\end{array}$ & $\begin{array}{l}3.29 \\
1.37\end{array}$ & $\begin{array}{l}2.85 \\
3.15\end{array}$ & $\begin{array}{c}3.55 \\
.8\end{array}$ & 0.003 \\
\hline $\mathrm{SNA}^{\circ}$ & $\begin{array}{c}\text { Female } \\
\text { Male }\end{array}$ & $\begin{array}{l}83.12 \\
81.82\end{array}$ & $\begin{array}{c}3.8 \\
3.65\end{array}$ & $\begin{array}{c}82.9 \\
81.65\end{array}$ & 0.103 \\
\hline $\mathrm{SNB}^{\circ}$ & $\begin{array}{c}\text { Female } \\
\text { Male }\end{array}$ & $\begin{array}{l}79.84 \\
80.47\end{array}$ & $\begin{array}{l}4.23 \\
3.69\end{array}$ & $\begin{array}{l}80.15 \\
80.15\end{array}$ & 0.448 \\
\hline Ar-Go-Me ${ }^{0}$ & $\begin{array}{c}\text { Female } \\
\text { Male }\end{array}$ & $\begin{array}{l}123.35 \\
121.44\end{array}$ & $\begin{array}{l}6.98 \\
9.35\end{array}$ & $\begin{array}{c}122.35 \\
123.3\end{array}$ & 0.277 \\
\hline Alveolar bone height [mm] & $\begin{array}{c}\text { Female } \\
\text { Male }\end{array}$ & $\begin{array}{c}12.71 \\
13.4\end{array}$ & $\begin{array}{l}2.82 \\
2.57\end{array}$ & $\begin{array}{l}12.45 \\
13.15\end{array}$ & 0.226 \\
\hline Basal bone width [mm] & $\begin{array}{c}\text { Female } \\
\text { Male }\end{array}$ & $\begin{array}{l}7.11 \\
7.32\end{array}$ & $\begin{array}{l}1.47 \\
1.76\end{array}$ & $\begin{array}{l}7.2 \\
7.5\end{array}$ & 0.536 \\
\hline Gonion-Nerve [mm] & $\begin{array}{c}\text { Female } \\
\text { Male }\end{array}$ & $\begin{array}{l}16.68 \\
19.28\end{array}$ & $\begin{array}{l}3.03 \\
3.06\end{array}$ & $\begin{array}{l}16.95 \\
19.15\end{array}$ & $<0.001$ \\
\hline
\end{tabular}

*Independent t-test, $\mathrm{p}<0.05 ; \mathrm{SD}$ — standard deviation

Table 2. Mean symphyseal measurements in females and males

\begin{tabular}{lccccc}
\hline Variable & Sex & Mean & Standard deviation & Median & Significance \\
\hline Symphyseal height [mm] & Female & 18.25 & 2.2 & 18.1 & $<0.001$ \\
& Male & 21.22 & 2.04 & 21.5 & 0.005 \\
Symphyseal thickness [mm] & Female & 11.92 & 1.68 & 12.15 & 13.15 \\
\\
Height to thick ratio [\%] & Male & 12.95 & 1.75 & 1.53 & 0.029 \\
& Female & 1.55 & 0.22 & 1.63 & \\
\hline
\end{tabular}

less than males by about $1 \mathrm{~mm}(p=0.005)$. Table 3 presents the measured values in each skeletal class.

\section{Association between symphysis measurements and skeletal morphology}

Table 4 shows the correlations between symphysis dimensions and multiple skeletal measurements. In females, there was a statistically significant but weak correlation between $\mathrm{SNA}^{\circ}$ and symphyseal height $(r=0.35, p=0.021)$ and symphyseal thickness $(r=0.4$, $p=0.021)$. There was also a strong inverse relationship between symphyseal ratio and basal width $(r=-0.71, p<0.001)$. In males, significant correlations were noted between the three symphyseal measurements and Gonial angle. Table 5 presents the correlation between anteroposterior skeletal classification by $\mathrm{ANB}^{\circ}$ and the three symphyseal dimensions. None of the correlations was statistically significant.

Three multivariate models were produced using stepwise multiple regression analysis for symphyseal height, thickness, and ratio. The first model (Table 5) used the symphyseal height as the dependent var- iable, Gonion-Nerve ( $p<0.001)$, and Gonial angle ( $p=0.005$ ) were the only significant variables. For every $1 \mathrm{~mm}$ increase in Gonion-Nerve, the symphysis height increases by $0.37 \mathrm{~mm}$ and for every 1 degree increase in the Gonial angle, the symphysis height increases by $0.11 \mathrm{~mm}$. For symphyseal thickness, basal width ( $p<0.001)$, Gonion-Nerve $(p=0.01)$, and alveolar height $(p=0.18)$ showed statistical significance. The symphyseal thickness relationship was proportional to basal width and inverse to alveolar height. Basal bone width $(p<0.001)$ and alveolar bone height ( $p=0.015$ ) showed significant association with symphysis ratio (Table 6).

\section{DISCUSSION}

This study was conducted to determine associations between symphysis height, thickness, and ratio and multiple skeletal variables and using a modified analysis from two previous studies $[8,17]$. The modified analysis utilised the bisecting line of the Gonial angle to locate the landmark 'nerve' point. This land- 
Table 3. Mean symphyseal measurements in each skeletal classification

\begin{tabular}{lccccc}
\hline Variable & Class & N & Mean & Standard deviation & Median \\
\hline Symphyseal height [mm] & Class III & 33 & 20.4 & 2.5 & 20.2 \\
& Class I & 29 & 19.32 & 2.34 & 19.5 \\
& Class II & 28 & 19.48 & 2.85 & 19.1 \\
Symphyseal thickness [mm] & Total & 90 & 19.77 & 2.59 & 19.5 \\
& Class III & 33 & 12.43 & 1.99 & 12.7 \\
& Class I & 29 & 12.27 & 1.68 & 12.2 \\
Height/thick ratio [\%] & Class II & 28 & 12.65 & 1.66 & 12.7 \\
& Total & 90 & 12.45 & 1.78 & 12.5 \\
& Class III & 33 & 1.68 & 0.3 & 1.63 \\
& Class I & 29 & 1.59 & 0.21 & 1.62 \\
& Class II & 28 & 1.55 & 0.23 & 1.55 \\
\hline
\end{tabular}

Table 4. Correlations between symphyseal measurements and skeletal pattern in females and males

\begin{tabular}{|c|c|c|c|c|c|c|c|c|}
\hline Symphyseal measurement & Correlation & $\mathrm{ANB}^{\circ}$ & SNA ${ }^{\circ}$ & SNB $^{\circ}$ & $\mathrm{Ar}-\mathrm{Go}_{\mathrm{O}} \mathrm{Me}^{0}$ & $\begin{array}{c}\text { Alveolar } \\
\text { height [mm] }\end{array}$ & $\begin{array}{l}\text { Basal width } \\
\text { [mm] }\end{array}$ & $\begin{array}{c}\text { Gonion-Nerve } \\
{[\mathrm{mm}]}\end{array}$ \\
\hline \multicolumn{9}{|l|}{ Females $(n=44)$} \\
\hline Symphyseal height & $\begin{array}{c}r \\
\text { Sig. }\end{array}$ & $\begin{array}{c}0.18 \\
0.252\end{array}$ & $\begin{array}{c}0.35 \\
0.021\end{array}$ & $\begin{array}{c}0.19 \\
0.206\end{array}$ & $\begin{array}{l}-0.05 \\
0.751\end{array}$ & $\begin{array}{l}-0.02 \\
0.881\end{array}$ & $\begin{array}{l}-0.12 \\
0.435\end{array}$ & $\begin{array}{c}0.21 \\
0.175\end{array}$ \\
\hline Symphyseal thickness & $\begin{array}{c}r \\
\text { Sig. }\end{array}$ & $\begin{array}{c}0.22 \\
0.252\end{array}$ & $\begin{array}{c}0.4 \\
0.021\end{array}$ & $\begin{array}{c}0.21 \\
0.206\end{array}$ & $\begin{array}{l}-0.1 \\
0.751\end{array}$ & $\begin{array}{l}-0.16 \\
0.881\end{array}$ & $\begin{array}{c}0.57 \\
0.435\end{array}$ & $\begin{array}{c}0.15 \\
0.175\end{array}$ \\
\hline Height/thickness ratio & $\begin{array}{c}r \\
\text { Sig. }\end{array}$ & $\begin{array}{l}-0.09 \\
0.566\end{array}$ & $\begin{array}{l}-0.14 \\
0.367\end{array}$ & $\begin{array}{l}-0.07 \\
0.669\end{array}$ & $\begin{array}{c}0.06 \\
0.721\end{array}$ & $\begin{array}{c}0.15 \\
0.343\end{array}$ & $\begin{array}{l}-0.71 \\
<0.001\end{array}$ & $\begin{array}{c}0.01 \\
0.969\end{array}$ \\
\hline \multicolumn{9}{|l|}{ Males $(n=46)$} \\
\hline Symphyseal height & $\begin{array}{c}r \\
\text { Sig. }\end{array}$ & $\begin{array}{c}0.1 \\
0.518\end{array}$ & $\begin{array}{c}0.13 \\
0.374\end{array}$ & $\begin{array}{c}0.05 \\
0.754\end{array}$ & $\begin{array}{c}0.37 \\
0.012\end{array}$ & $\begin{array}{l}-0.14 \\
0.355\end{array}$ & $\begin{array}{l}-0.22 \\
0.134\end{array}$ & $\begin{array}{l}-0.08 \\
0.598\end{array}$ \\
\hline Symphyseal thickness & $\begin{array}{c}r \\
\text { Sig. }\end{array}$ & $\begin{array}{c}0.2 \\
0.190\end{array}$ & $\begin{array}{c}0.14 \\
0.345\end{array}$ & $\begin{array}{l}-0.03 \\
0.870\end{array}$ & $\begin{array}{l}-0.49 \\
0.001\end{array}$ & $\begin{array}{l}-0.23 \\
0.124\end{array}$ & $\begin{array}{c}0.68 \\
<0.001\end{array}$ & $\begin{array}{c}0.36 \\
0.033\end{array}$ \\
\hline Height/thickness ratio & $\begin{array}{c}r \\
\text { Sig. }\end{array}$ & $\begin{array}{l}-0.18 \\
0.230\end{array}$ & $\begin{array}{l}-0.07 \\
0.652\end{array}$ & $\begin{array}{l}0.08 \\
0.584\end{array}$ & $\begin{array}{c}0.66 \\
<0.001\end{array}$ & $\begin{array}{c}0.15 \\
0.311\end{array}$ & $\begin{array}{l}-0.75 \\
<0.001\end{array}$ & $\begin{array}{c}-0.3 \\
0.040\end{array}$ \\
\hline
\end{tabular}

Table 5. Correlations between symphyseal measurements and sagittal skeletal classification

\begin{tabular}{lcccc}
\hline Anteroposterior skeletal pattern & Correlation & Symphyseal height & Symphyseal thickness & Height/thick ratio \\
\hline Class I $(\mathrm{n}=29)$ & $\mathrm{r}$ & 0.04 & 0.06 & 0.003 \\
& Sig. & 0.831 & 0.751 & 0.990 \\
Class II $(\mathrm{n}=28)$ & $\mathrm{r}$ & 0.06 & 0.12 & -0.04 \\
& Sig. & 0.765 & 0.548 & 0.850 \\
Class III $(\mathrm{n}=33)$ & $\mathrm{r}$ & 0.29 & 0.18 & -0.08 \\
& Sig. & 0.108 & 0.311 & 0.662 \\
\hline
\end{tabular}

mark was more reproducible than the ramus body syncline 'RBS' point, which is formed by the intersection of the line from Gonion to posterior alveolar 'PAP' point. PAP point is the most posterior inferior point on the anterior border of the ramus. Replacing PAP and RBS with the new landmarks increased the accuracy of data identification in this study.
Gonion-Nerve measurement represents the intersection of the ramus with the body of the mandible. Its correlation with the symphyseal height demonstrates that when the Gonion-Nerve distance in the posterior mandible is increased, the height will increase in the anterior of the mandible. Also, as the Gonion-Nerve distance increased, the thickness of the 
Table 6. Multiple linear regression models for association between symphyseal measurements and skeletal pattern

\begin{tabular}{|c|c|c|c|c|c|c|}
\hline \multirow[t]{2}{*}{ Model } & \multicolumn{2}{|c|}{ Unstandardised coefficients } & \multirow{2}{*}{$\frac{\text { Standardised coefficients }}{\text { Beta }}$} & \multirow[t]{2}{*}{$\mathbf{t}$} & \multirow[t]{2}{*}{ Significance } & \multirow[t]{2}{*}{ Adjusted $\mathbf{R}^{2}$} \\
\hline & B & Standard error & & & & \\
\hline Symphyseal height [mm] & & & & & & 0.14 \\
\hline (Constant) & 0.16 & 5.61 & & 0.03 & 0.977 & \\
\hline Gonion-Nerve & 0.37 & 0.09 & 0.47 & 3.96 & $<0.001$ & \\
\hline Ar-Go-Me (Gonial angle) & 0.11 & 0.04 & 0.34 & 2.88 & 0.005 & \\
\hline Symphyseal thickness [mm] & & & & & & 0.44 \\
\hline (Constant) & 7.45 & 1.07 & & 6.96 & $<0.001$ & \\
\hline Basal bone width & 0.63 & 0.09 & 0.57 & 6.96 & $<0.001$ & \\
\hline Gonion-Nerve & 0.12 & 0.05 & 0.22 & 2.64 & 0.010 & \\
\hline Alveolar bone height & -0.13 & 0.05 & -0.2 & -2.42 & 0.018 & \\
\hline Height to thickness ratio [\%] & & & & & & 0.51 \\
\hline (Constant) & 2.19 & 0.13 & & 17.3 & $<0.001$ & \\
\hline Basal bone width & -0.11 & 0.01 & -0.7 & -9.44 & $<0.001$ & \\
\hline Alveolar bone height & 0.018 & 0.01 & 0.18 & 2.48 & 0.015 & \\
\hline
\end{tabular}

symphysis also increased ( $p=0.002)$. So, measuring the Gonion-Nerve can give an estimate of both the height and thickness of the symphysis. Future studies are warranted to fully investigate this measurement in its correlation with symphyseal dimensions.

This study found sexual dimorphism in regard to mean symphyseal heights. The mean symphyseal height was greater in males $(21.22 \mathrm{~mm}$ ) compared to females $(18.25 \mathrm{~mm})$. This result is supported by another study which found that the symphyseal vertical dimension is larger in males than females [11]. Moreover, the height to thickness ratio was close to 1.5 in both males and females suggesting that overall, normal height is 1.5 times larger than the thickness. This is different form a previous study that reported that symphysis ratio is smaller in males compared to females [2]. This could be attributed to the differences in sample ethnicity and methodology applied in the two studies.

his study assessed the correlation between anteroposterior skeletal pattern and symphysis dimensions. There was no significant relationship between symphysis height, thickness or ratio and $\mathrm{ANB}^{\circ}, \mathrm{SNA}^{\circ}$, or $\mathrm{SNB}^{\circ}$ in both males and females except for $\mathrm{SNA}^{\circ}$. This variable had a weak to moderate correlation with symphyseal height and thickness but not ratio in females.

When $\mathrm{ANB}^{\circ}$ was analysed categorically, no significant associations were noted between $\mathrm{ANB}^{\circ}$ values in each skeletal class and symphysis height, thickness, or ratio. This disagrees with Torgut and Akan [19] who found that symphyseal vertical development is negatively related to $\mathrm{ANB}^{\circ}$. It also contradicts with Al-Khateeb et al. [3] results who found a significant relationship between skeletal class III and the vertical dimension of the mandibular symphysis. Al-Khateeb et al. [3] used a different line extending between point infradentale, which is the most anterior superior point on the buccal alveolar crest of the mandible, and Menton to measure the total length of the mandibular symphysis. Thus, combining both the symphysis and alveolus in the total length of the mandibular symphysis. Meanwhile, in this study, the alveolus and the symphysis were separated by line B to BI2. The symphysis length is the distance from the midpoint of a line connecting $\mathrm{B}$ to $\mathrm{Bl} 2$, or saj2, to Menton.

A recent study evaluated symphyseal dimensions according to sagittal and vertical skeletal relationships in both genders. It found that males had increased mandibular symphysis surface area and linear dimensions compared to females. Also, subjects with skeletal class II relationship had greater dentoalveolar length compared to those with class I and III. Chin length was also greater in subjects with average mandibular plane angle [14].

Our study found a strong positive correlation ( $p<0.001$ ) between Gonial angle and symphysis ratio in males as compared to females $(p=0.721)$. This is expected since symphysis ratio is the height divided by thickness and thus the ratio would be greater in 
hyperdivergent subjects. Similar to our study, Aki et al. [2] divided the chin into symphyseal and alveolar components utilizing B-point, and showed that in individuals with receding chins, the symphysis ratio, Gonial angle, and both the lower and anterior facial height would be large. In high angle patients, dentoalveolar compensation of the alveolar bone occurs by vertical lengthening [16]. This compensation is further explained in previous studies $[3,5]$ which have attributed vertical growth of the symphysis to the supraeruption of dentition due to the absence of antagonist teeth in open bite cases.

The Gonial angle showed a significant negative correlation to symphysis thickness $(p=0.001)$. This relationship can be demonstrated in deep bite cases that have smaller values for Gonial angle [7] where the increase in thickness could be attributed to the masseter muscle hyperfunction [18]. This also explains the larger ratio in open bite cases that have no incisor contact [2].

This study found no correlation between alveolar bone height and symphyseal height, thickness, or ratio in both genders. This might be due to the fact that alveolar bone height is mainly affected by lower incisor position and root length (measured from midpoint of the CEJ line to the midpoint of B-BI2 line) [20], independent of symphyseal height. This study however, only assessed height and not thickness of the alveolar bone. Foosiri et al. [10] evaluated alveolar thickness in relation symphyseal ratio and found that the ratio is negatively correlated with buccal and lingual alveolar bone thickness. Future studies may consider evaluating both dimensions of the alveolar bone.

The multiple linear regression model for symphysis height showed a statistically significant association with Gonial angle and Gonion-Nerve measurements, rejecting the hypothesis of this study. This finding was confirmed in previous studies $[6,15]$ and is also consistent with Kasai et al. [13] who showed a positive relationship between Gonial angle and symphyseal height. Moreover, Ahn et al. [1] found that vertical skeletal dimension was related to the symphyseal morphology more than transverse or anteroposterior dimensions. Therefore, it can be concluded that individuals long anterior face height had elongated symphysis, and those with short face height have wide symphysis. Regarding the multiple regression model for symphyseal thickness, basal bone width and alveolar bone height were entered in addition to Gonion-Nerve. Basal bone width is more related to symphysis thickness, as it is measured more superior and parallel to symphysis thickness on the cephalograms. In terms of the model for symphysis ratio, basal width and alveolar height were significantly associated with the ratio of height to thickness.

\section{Limitations of the study}

This study had several limitations. The study used two-dimensional lateral cephalograms and did not assess the structures in all three-dimensions. Also, due to the stringent inclusion criteria applied in this study, the sample size included was small. Large future three-dimensional studies are warranted to confirm the results and to evaluate additional variables in relation to symphyseal dimensions. Further studying of Gonion-Nerve in individuals with different anteroposterior skeletal patterns is recommended to fully understand the association between this variable and symphysis dimensions. This study shed light on the morphological features of the mandibular symphysis. These features can be assessed clinically to ensure proper orthodontic diagnosis and planning and to prevent movement of teeth out of the symphyseal envelope during treatment.

\section{CONCLUSIONS}

The mean symphyseal height, thickness, and ratio of height to thickness were significantly greater in males than in females.

Symphyseal height, thickness, and ratio were not significantly associated with anteroposterior skeletal classification $\left(\mathrm{ANB}^{\circ}\right)$.

Symphyseal height, thickness, and ratio were significantly associated with Gonial angle (vertical skeletal pattern), Gonion-Nerve, basal bone width, and alveolar bone height.

Future studies are warranted to evaluate Gonion-Nerve measurements concerning the symphysis in relation to different skeletal pattern.

\section{Conflict of interest: None declared}

\section{REFERENCES}

1. Ahn MS, Shin SM, Yamaguchi T, et al. Relationship between the maxillofacial skeletal pattern and the morphology of the mandibular symphysis: Structural equation modeling. Korean J Orthod. 2019; 49(3): 170-180, doi: 10.4041/ kjod.2019.49.3.170, indexed in Pubmed: 31149607.

2. Aki T, Nanda RS, Currier GF, et al. Assessment of symphysis morphology as a predictor of the direction of mandibular growth. Am J Orthod Dentofacial Orthop. 1994; 106(1): 60-69, doi: 10.1016/S0889-5406(94)70022-2, indexed in Pubmed: 8017351. 
3. Al-Khateeb SN, Al Maaitah EF, Abu Alhaija ES, et al. Mandibular symphysis morphology and dimensions in different anteroposterior jaw relationships. Angle Orthod. 2014; 84(2): 304-309, doi: 10.2319/030513-185.1, indexed in Pubmed: 23914822.

4. Arruda K, Neto JV, Almeida G. Assessment of the mandibular symphysis of Caucasian Brazilian adults with well-balanced faces and normal occlusion: the influence of gender and facial type. Dental Press J Orthod. 2012; 17(3): 40-50, doi: 10.1590/s2176-94512012000300012.

5. Buschang PH, Julien K, Sachdeva R, et al. Childhood and pubertal growth changes of the human symphysis. Angle Orthod. 1992; 62(3): 203-210, doi: 10.1043/0003-3219(1992)062<0203:CAPGCO>2.0.CO;2, indexed in Pubmed: 1416240.

6. Buschang PH, Jacob H, Carrillo R. The morphological characteristics, growth, and etiology of the hyperdivergent phenotype. Seminars in Orthodontics. 2013; 19(4): 212-226, doi: 10.1053/j.sodo.2013.07.002.

7. Ceylan I, Eröz UB. The effects of overbite on the maxillary and mandibular morphology. Angle Orthod. 2001; 71(2): 110-115, doi: 10.1043/0003-3219(2001)071<0110:TEOOOT>2.0. CO;2, indexed in Pubmed: 11302586.

8. Chung CJ, Jung S, Baik HS. Morphological characteristics of the symphyseal region in adult skeletal Class III crossbite and openbite malocclusions. Angle Orthod. 2008; 78(1): 38-43, doi: 10.2319/101606-427.1, indexed in Pubmed: 18193946.

9. Evans JD. Straightforward statistics for the behavioral sciences. Brooks/Cole Publishing, Pacific Grove, CA 1996.

10. Foosiri P, Mahatumarat K, Panmekiate $S$. Relationship between mandibular symphysis dimensions and mandibular anterior alveolar bone thickness as assessed with conebeam computed tomography. Dental Press J Orthod. 2018; 23(1): 54-62, doi: 10.1590/2177-6709.23.1.054-062.oar, indexed in Pubmed: 29791685.

11. Gómez Y, García-Sanz V, Zamora N, et al. Associations between mandibular symphysis form and craniofacial structures. Oral Radiol. 2018; 34(2): 161-171, doi: 10.1007/ s11282-017-0292-x, indexed in Pubmed: 30484128.

12. Haskell BS. The human chin and its relationship to mandibular morphology. Angle Orthod. 1979; 49(3): 153-166, doi:
10.1043/0003-3219(1979)049<0153:THCAIR>2.0.CO;2, indexed in Pubmed: 290281.

13. Kasai K, Enomoto Y, Ogawa T, et al. Morphological characteristics of vertical sections of the mandible obtained by CT scanning. Anthropol Sci. 1996; 104(3): 187-198, doi: 10.1537/ase.104.187.

14. Linjawi Al, Afify AR, Baeshen HA, et al. Mandibular symphysis dimensions in different sagittal and vertical skeletal relationships. Saudi J Biol Sci. 2021; 28(1): 280-285, doi: 10.1016/j.sjbs.2020.09.062, indexed in Pubmed: 33424307.

15. Puigdollers A, Molina-Berlanga N, Llopis-Perez J, et al. Lower incisor dentoalveolar compensation and symphysis dimensions among Class I and III malocclusion patients with different facial vertical skeletal patterns. Angle Orthod. 2013; 83(6): 948-955, doi: 10.2319/011913-48.1, indexed in Pubmed: 23758599.

16. Sadek MM, Sabet NE, Hassan IT, et al. Alveolar bone mapping in subjects with different vertical facial dimensions. Eur J Orthod. 2015; 37(2): 194-201, doi: 10.1093/ejo/ cju034, indexed in Pubmed: 25114124.

17. Suri S, Ross RB, Tompson BD. Mandibular morphology and growth with and without hypodontia in subjects with Pierre Robin sequence. Am J Orthod Dentofacial Orthop. 2006; 130(1): 37-46, doi: 10.1016/j.ajodo.2005.09.026, indexed in Pubmed: 16849070.

18. Swasty D, Lee JS, Huang JC, et al. Anthropometric analysis of the human mandibular cortical bone as assessed by cone-beam computed tomography. J Oral Maxillofac Surg. 2009; 67(3): 491-500, doi: 10.1016/j.joms.2008.06.089, indexed in Pubmed: 19231771.

19. Torgut AG, Akan S. Mandibular symphysis morphology in different skeletal malocclusions and its correlation with uvulo-glossopharyngeal structures. Cranio. 2021; 39(6): 533-540, doi: 10.1080/08869634.2019.1677311, indexed in Pubmed: 31601164.

20. Wehrbein H, Bauer W, Diedrich P. Mandibular incisors, alveolar bone, and symphysis after orthodontic treatment. A retrospective study. Am J Orthod Dentofacial Orthop. 1996; 110(3): 239-246, doi: 10.1016/s08895406(96)80006-0, indexed in Pubmed: 8814023. 